\title{
Índice de adaptação e tempo letal da lagarta-do-cartucho em milho Bt
}

\author{
Matheus Soares Waquil(1), Eliseu José Guedes Pereira(2), Samantha Stefannie de Sousa Carvalho( ${ }^{(3)}$, \\ Rafael Major Pitta ${ }^{(4)}$, José Magid Waquil( ${ }^{(5)}$ e Simone Martins Mendes ${ }^{(3)}$
}

\begin{abstract}
(1)DuPont do Brasil, Alameda Itapecuru, no 506, Alphaville, CEP 06454-080 Barueri, SP, Brasil. E-mail: mswaquil@gmail.com (2)Universidade Federal de Viçosa, Departamento de Entomologia, Campus Universitário, CEP 36570-000 Viçosa, MG, Brasil. E-mail: eliseu.pereira@ufv.br (3)Embrapa Milho e Sorgo, Rodovia MG-424, Km 45, CEP 35701-970 Sete Lagoas, MG, Brasil. E-mail: samanthastefannie@hotmail.com, simone.mendes@embrapa.br ${ }^{(4)}$ Embrapa Agrossilvipastoril, Rodovia dos Pioneiros MT-222, Km 2,5, Zona Rural, Caixa Postal 343, CEP 78550-970 Sinop, MT, Brasil. E-mail: rafael.pitta@embrapa.br ${ }^{(5)}$ Consultoria \& Treinamento em Manejo Integrado de Pragas Ltda., Rua Jovelino Lanza, oㅡ 210, Jardim Arizona, CEP 35700-353 Sete Lagoas, MG, Brasil. E-mail: jmwaquil@gmail.com
\end{abstract}

Resumo - O objetivo deste trabalho foi avaliar o índice de adaptação e o tempo letal de populações da lagarta-do-cartucho [Spodoptera frugiperda (Lepidoptera: Noctuidae)] em milho Bt que expressa as proteínas Cry1Ab, Cry1F, Cry1A.105/Cry2Ab2 e Vip3Aa20. Três bioensaios foram conduzidos com lagartas coletadas em Inhaúma, MG, e em Sinop, MT. As lagartas dessas populações foram alimentadas com folhas de milho não Bt e Bt. As seguintes variáveis foram avaliadas: sobrevivência larval, biomassa de pupas e período de desenvolvimento larval. Em seguida, foram calculados os índices de adaptação e o tempo letal dessas populações. Para a análise do tempo letal, também foram utilizados dados de mortalidade de uma população obtida de milho Bt Cry1F em Piumhi, MG. O milho Bt Cry1 Ab apresentou eficiência limitada, mas duradoura. Já os milhos Bt Cry1A.105/Cry2Ab2 e Vip3Aa20 reduziram o desempenho de S. frugiperda, respectivamente, a menos de 5 e $0 \%$, independentemente da origem da colônia. A população originada de Sinop apresentou alto desempenho larval no milho Bt Cry $1 \mathrm{~F}$, o que mostra sua resistência a essa proteína e certo nível de custo adaptativo. $\mathrm{O}$ tempo letal pode ser uma variável indicadora de evolução de resistência, pois é maior para as populações com maior adaptação.

Termos para indexação: Spodoptera frugiperda, Zea mays, desempenho larval, manejo da resistência, manejo integrado de pragas, milho transgênico.

\section{Fitness index and lethal time of fall armyworm on Bt corn}

Abstract - The objective of this work was to evaluate the fitness index and lethal time of fall armyworm [Spodoptera frugiperda (Lepidoptera: Noctuidae)] populations on Bt corn expressing the Cry1Ab, Cry1F, Cry1A.105/Cry2Ab2, and Vip3Aa20 proteins. Three bioassays were conducted with larvae collected at the municipality of Inhaúma, in the state of Minas Gerais, and at the municipality of Sinop, in the state of Mato Grosso, Brazil. Larvae from these populations were fed with leaves of non-Bt and Bt corn. The following variables were evaluated: larval survival, pupae mass, and larval development period. Then, the fitness indexes and lethal time of these populations were calculated. For lethal time analysis, mortality data of a population collected from Cry1F Bt corn in the municipality of Piumhi, in the state of Minas Gerais, were also used. The Cry1Ab Bt corn showed a limited but durable efficiency. The Cry1A.105/Cry2Ab2 and Vip3Aa20 Bt corn reduced $S$. frugiperda performance, respectively, to less than 5 and $0 \%$, regardless of the origin of the colony. The population from Sinop showed high larval performance in Cry1F Bt corn, showing its resistance to this protein and a certain level of fitness cost. The lethal time can be a variable that indicates evolution of resistance, since it is greater for populations with greater fitness.

Index terms: Spodoptera frugiperda, Zea mays, larval performance, resistance management, integrated pest management, transgenic corn.

\section{Introdução}

Somente na cultura do milho (Zea mays L.), no Brasil, os insetos-praga podem causar perdas aproximadas de $20 \%$ na produção, de cerca de 2 bilhões de dólares (Oliveira et al., 2014). Para o manejo da principal praga da cultura, a lagarta-docartucho [Spodoptera frugiperda (J.E. Smith, 1797)
(Lepidoptera: Noctuidae)], têm-se recomendado diversos métodos de controle de forma integrada, como a tecnologia $\mathrm{Bt}$ (Boas práticas agronômicas aplicadas a plantas geneticamente modificadas resistentes a insetos: manejo integrado de pragas, 2014).

Em razão da alta eficácia do milho Bt no controle de lagartas, sua adoção foi rápida no Brasil, e, na safra 2013/2014, o milho transgênico foi utilizado em 
$81,6 \%$ da área cultivada (Céleres, 2013). No entanto, com o uso intensivo dos híbridos Bt, principalmente dos que expressam a proteína Cry $1 \mathrm{~F}$, vários casos de falha no controle de $S$. frugiperda foram registrados em diversas regiões brasileiras. Uma possível explicação é o baixo uso de refúgio (Resende et al., 2014), prática que tem sido recomendada para o manejo da resistência (Martinelli \& Omoto, 2005).

Atualmente, no Brasil, estão liberadas, para comercialização, 16 tecnologias transgênicas para o controle de pragas na cultura do milho, que incluem eventos simples ou piramidados por meio de combinação ou estaqueamento de genes $b t$ (Comissão Técnica Nacional de Biossegurança, 2009). Esses eventos têm como espécies-alvo os lepidópteros-praga e uma espécie de Coleoptera, a larva de diabrótica [Diabrotica speciosa (LeConte)] (Comissão Técnica Nacional de Biossegurança, 2009). Após a aprovação comercial dessas proteínas, foi possível utilizar diferentes combinações destes mesmos genes $b t$ em híbridos de milho, para maior eficiência no controle das pragas-alvo, para ampliação do espectro de ação e como estratégia para o manejo da resistência (Martinelli \& Omoto, 2005).

Contudo, em menos de 20 anos de uso da tecnologia $\mathrm{Bt}$, já foram registradas quatro espécies de Lepidoptera e uma de Coleoptera resistentes às proteínas $\mathrm{Bt}$ (Tabashnik et al., 2014). Entre os casos de resistência observados em outros países, os mais relevantes, para o Brasil, foram os registros de S. frugiperda resistente ao milho Bt Cry1F, em Porto Rico (Storer et al., 2010) e nos Estados Unidos (Huang et al., 2014). No Brasil, além da constatação recente de falha no controle de $S$. frugiperda em vários híbridos de milho Bt Cry1F, Farias et al. (2014) também documentaram essa resistência em uma população do inseto, no Oeste da Bahia (BA25R).

Assim, vários estudos têm sido conduzidos para avaliar as lagartas quanto à adaptação em diferentes hospedeiros (Boregas et al., 2013) e à resistência às proteínas Bt (Farias et al., 2014). Nos Estados Unidos, Pereira etal.(2008), por exemplo, utilizaram populações suscetíveis e resistentes à proteína Cry1F, obtidas em 30 ciclos de seleção de Ostrinia nubilalis (Hübner), para estimar o custo adaptativo associado à resistência, ou seja, a redução no desempenho ou a adaptação em relação à população selvagem não resistente que se alimentou com o milho não Bt. Assim, a determinação periódica do nível de adaptação das espécies-alvo da tecnologia $\mathrm{Bt}$, nas plantas transgênicas, torna-se fundamental para antecipar medidas de manejo da resistência, potenciais ou mitigatórias, nos casos de riscos iminentes.

O objetivo deste trabalho foi avaliar o índice de adaptação e o tempo letal de populações da lagartado-cartucho [Spodoptera frugiperda (Lepidoptera: Noctuidae)] em milho Bt que expressa as proteínas Cry1Ab, Cry1F, Cry1A.105/Cry2Ab2 e Vip3Aa20.

\section{Material e Métodos}

Foram conduzidos três bioensaios no laboratório de Ecotoxicologia e Manejo de Insetos da Embrapa Milho e Sorgo, em Sete Lagoas, MG, para avaliar o desempenho e o tempo letal de quatro populações de $S$. frugiperda em milho Bt. As lagartas de S. frugiperda foram coletadas: em milho Bt Cry1 Ab, no município

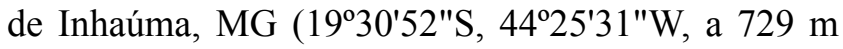
de altitude), nas safras 2008/2009 e 2010/2011; e em milho Bt Cry1A.105/Cry2Ab2, no município de Sinop, MT (11 $51^{\prime} 37^{\prime \prime S}, 55^{\circ} 37^{\prime} 11^{\prime \prime W}$, a $375 \mathrm{~m}$ de altitude), na safrinha 2014. Para a determinação do tempo letal, além dessas duas populações coletadas em 2010/2011 e 2014, foi utilizada uma população coletada em milho Bt Cry1F, no município de Piumhi, MG $\left(20^{\circ} 33^{\prime} 20^{\prime \prime} \mathrm{S}\right.$, 4601'30"W, a $759 \mathrm{~m}$ de altitude), na safra 2010/2011.

Em Inhaúma, o milho Bt Cry1Ab já vinha sendo cultivado desde 2008/2009; portanto, a coleta dos insetos foi realizada durante a terceira safra de uso da tecnologia Bt. Como testemunha, foram utilizados insetos coletados em milho não Bt (DKB 390 e Impacto). Já na safra 2013/2014, com a divulgação da ocorrência de lagartas de $S$. frugiperda em milho Bt em várias regiões brasileiras, amostras de $S$. frugiperda coletadas em milho Bt Cry1A.105/Cry2Ab2, na região de Sinop, foram encaminhadas à Embrapa Milho e Sorgo, onde foi estabelecida uma colônia. As coletas, a manutenção das colônias de insetos no laboratório e a determinação do índice de adaptação foram realizadas de acordo com os métodos descritos por Sousa (2011).

Os híbridos utilizados para alimentação das lagartas foram: $\mathrm{P} 30 \mathrm{~F} 35$ para as proteínas Cry1F (Milho $\mathrm{Bt} \mathrm{Hx}$ ) e Cry1Ab (Milho Bt YG); DKB 390 não Bt (Milho não Bt DKB) e DKB 390 Bt para a proteína Cry1A.105/ Cry2Ab2 (Milho Bt VT PRO); e Impacto não Bt (Milho não Bt Imp) e Impacto Bt para a proteína Vip3Aa20 (Milho Bt Vip). Os milhos Bt Cry1Ab, Cry1F, Cry1A.105/Cry2Ab2 e Vip3Aa20 foram cultivados 
no campo, na área experimental da Embrapa Milho e Sorgo. As sementes foram obtidas nas empresas detentoras dos respectivos eventos Bt estudados, e o cultivo seguiu as práticas agrícolas recomendadas para a região (Cruz, 2010), exceto o uso de inseticida, para não interferir com os resultados. Os bioensaios foram iniciados quando havia plantas, dos milhos a serem testados, nos estádios V4-V8, para alimentar as lagartas, de acordo com a metodologia preconizada por Sá et al. (2009) e Mendes et al. (2011), sob iluminação natural e em condições controladas de temperatura $\left(26 \pm 2^{\circ} \mathrm{C}\right)$ e umidade relativa $(60 \pm 10 \%)$.

Durante a condução dos bioensaios, foram anotadas as seguintes variáveis: sobrevivência (razão), a cada 2 ou 3 dias até a fase de pupa; biomassa ( $\mathrm{mg}$ ) de pupas; e período de desenvolvimento larval (dias), a partir da eclosão das larvas até o primeiro dia em que se observou a pupa. Neste dia, a pupa foi pesada em balança de precisão $(0,1 \mathrm{mg})$ e observada até a emergência do adulto. Ao final, foram calculados a sobrevivência larval, o período de desenvolvimento e a razão sexual. Em todos os bioensaios, utilizou-se o delineamento experimental inteiramente casualizado, com oito repetições, em arranjo fatorial que envolveu a combinação de duas colônias de lagartas (coletadas em milho não $\mathrm{Bt}$ e em milho $\mathrm{Bt}$ ) e de diferentes híbridos de milho $\mathrm{Bt}$ e não $\mathrm{Bt}$ utilizados na alimentação dessas lagartas.

Para avaliar o desempenho larval de $S$. frugiperda em híbridos de milho $\mathrm{Bt}$ que expressam diferentes proteínas, utilizou-se o índice de adaptação (IA) proposto por Boregas et al. (2013), que avalia o desempenho larval em diferentes hospedeiros alternativos, em que: IA $=$ sobrevivência larval $(\%) \times$ biomassa de pupas $(\mathrm{mg}) /$ período de desenvolvimento larval (dias); no cálculo do índice de adaptação, a biomassa de pupas foi utilizada para estimar a fecundidade dos adultos (Barah \& Sengupta, 1991). Com base neste índice, também calculou-se o índice relativo de adaptação, por meio da divisão do índice de adaptação de cada tratamento pelo índice de adaptação da testemunha (neste caso, lagartas oriundas de milho não Bt, alimentadas com milho não Bt); para expressar o valor em percentagem, o resultado dessa divisão foi multiplicado por 100 .

Para o cálculo da razão sexual para cada tratamento, foram anotados o número e o sexo dos adultos emergidos nos três bioensaios utilizados para estimar os índices de adaptação. A expressão usada para calcular a razão sexual $(\mathrm{RS})$ foi: $\mathrm{RS}=$ número de fêmeas / (número de machos + fêmeas). Os dados obtidos foram utilizados para calcular os índices de adaptação absoluto e relativo.

Os resultados foram submetidos ao teste de normalidade de Shapiro-Wilk, com auxílio do programa Excel (Microsoft Office, Microsoft, São Paulo, SP). Utilizou-se análise de variância (Anova) para testar a hipótese de nulidade, com uso do programa Minitab Statistical, versão 17 (Minitab Inc., State College, PA, EUA). Quando necessário, as médias foram discriminadas pelo teste de Fisher, a 5\% de probabilidade.

Para complementar a avaliação do desempenho de $S$. frugiperda nos diferentes milhos Bt, foi calculado o tempo letal. Para tanto, os dados de sobrevivência dos três bioensaios foram anotados periodicamente e utilizados para calcular a mortalidade de forma acumulada, com base no total de indivíduos mortos; em seguida, a mortalidade foi submetida à análise de regressão linear para determinar o tempo letal (Gomez et al., 1999). Para a análise de regressão, o tempo foi transformado em $\log _{10}$, e a percentagem de mortalidade foi usada diretamente e transformada em probit. Entretanto, como o ajuste dos dados (com base em $\mathrm{R}^{2}$ ) foi melhor sem a transformação da mortalidade em probit, escolheu-se a primeira opção. Com base nos dados estimados por meio da equação de regressão, também foi calculado o intervalo de confiança $(\mathrm{p}=95 \%)$ para o tempo letal médio $\left(\mathrm{TL}_{50}\right)$. As médias com superposição de intervalo de confiança foram consideradas equivalentes.

\section{Resultados e Discussão}

Para a análise da razão sexual, foram considerados apenas os tratamentos em que, pelo menos, 12 lagartas sobreviveram até a fase adulta. Não foram observadas diferenças entre os tratamentos nos três bioensaios (Tabelas 1 e 2), uma vez que a razão sexual média para os insetos coletados em milho Bt e não Bt foi, respectivamente, de 0,49 e 0,51. Assim, é possível afirmar que o consumo de plantas que expressam proteínas Bt não afeta a sobrevivência dos insetos em função do sexo; portanto, não houve a necessidade de incluir essa variável nas estimativas dos índices de adaptação. Tanto o índice de adaptação quanto o índice relativo de adaptação indicaram diferenças nas respostas das lagartas de colônias não Bt e Bt, coletadas 
na safra 2008/2009; no entanto, os índices obtidos na safra 2010/2011 não distinguiram esses dois tipos de colônias (Tabela 1).

$\mathrm{Na}$ safra 2008/2009, foram observadas diferenças entre colônias de insetos coletadas no milho Bt Cry1 $\mathrm{Ab}$ e nas áreas não $\mathrm{Bt}$, consideradas de refúgio. Os índices indicaram maior adaptação de $S$. frugiperda oriunda e alimentada em milho não $\mathrm{Bt}$, em contraste com as lagartas expostas pela primeira vez ao milho Bt. As lagartas oriundas do milho $\mathrm{Bt}$ apresentaram índice de adaptação intermediário, e não houve diferença nos índices de adaptação quando estas foram alimentadas com milho Bt ou não Bt. Dessa forma, o desempenho dos insetos previamente expostos à proteína $\mathrm{Bt}$ foi semelhante, independentemente do tipo de milho oferecido como alimento. Notou-se, ainda, que, para $S$. frugiperda oriunda de milho não $\mathrm{Bt}$ e alimentada com milho Bt Cry1 Ab, o índice relativo de adaptação foi cerca de $40 \%$ do observado na testemunha; porém, esse índice foi alto para se considerar esse evento eficiente no controle da espécie-alvo. Parte dessa baixa eficiência pode ser explicada pela interação entre a cultivar e o gene bt (CrylAb) (Waquil et al., 2002).

Em 2009, em relação aos insetos alimentados com milho Bt, as lagartas coletadas no milho Cry $1 \mathrm{Ab}$ apresentaram índice relativo de adaptação de $64 \%$, o que indica certo nível de resistência à proteína $\mathrm{Bt}$, como também observado em condições de campo (Mendes et al., 2011). Ao se comparar o índice relativo de adaptação dos insetos oriundos de plantas Bt com os das plantas não $\mathrm{Bt}$, alimentados no milho não $\mathrm{Bt}$, houve redução de mais de 35 pontos percentuais
(Tabela 1). Isso indica custo adaptativo dos insetos sobreviventes no milho Bt Cry1Ab. Desse modo, se confirmado, esse fato poderia tanto dificultar o estabelecimento da população resistente quanto possibilitar a reversão da suscetibilidade com a retirada do evento por algum período de tempo. Neste contexto, um esforço significativo tem sido feito pela indústria de sementes para a adoção de estratégias para o manejo da resistência, como o uso intensivo de área de refúgio estruturada e efetiva, ou seja, que atenda a todas as recomendações técnicas de cada produto (Boas práticas agronômicas aplicadas a plantas geneticamente modificadas resistentes a insetos: manejo integrado de pragas, 2014).

Contudo, o custo adaptativo associado à resistência às plantas $\mathrm{Bt}$ não foi observado, por exemplo, em Busseola fusca (Fuller) (Van Rensburg, 2007), embora tenha sido relatado em outras espécies de Lepidoptera, como Plutella xylostella (L.) (Groeters et al., 1994), Pectinophora gossypiella (Saunders) (Carrière et al., 2001), Trichoplusia ni (Hübner) (Janmaat \& Myers, 2005) e Helicoverpa armigera (Hübner) (Akhurst et al., 2003). Uma possível explicação é que, ao longo do tempo, o custo adaptativo pode ser reduzido por evolução subsequente (Coustau et al., 2000). Assim, todos os fatores que afetam a bioecologia das espécies-alvo são importantes na pressão de seleção e no custo adaptativo.

Para alguns insetos, o declínio da resistência à proteína $\mathrm{Bt}$, na ausência de seleção, tem sido reportado em laboratório (Ferré \& Van Rie, 2002; Gassmann et al., 2009). Este resultado pode ser explicado

Tabela 1. Média \pm erro-padrão do desempenho larval, estimado pelos índices de adaptação e pela razão sexual, de Spodoptera frugiperda proveniente de milho não Bt (Lagarta não Bt) e de milho Bt Cry1 Ab (Lagarta Bt), alimentada com folhas de milho não Bt e Bt Cry1Ab (Milho Bt) ${ }^{(1)}$.

\begin{tabular}{lcc}
\hline Tratamento & Índice de adaptação & Índice relativo de adaptação \\
\hline & & Safra $2008 / 2009$ \\
Lagarta não Bt/Milho não Bt & $7,50 \pm 0,39 \mathrm{a}$ & $100,00 \pm 5,23 \mathrm{a}$ \\
Lagarta Bt/Milho não Bt & $4,85 \pm 0,37 \mathrm{~b}$ & $64,67 \pm 4,88 \mathrm{~b}$ \\
Lagarta Bt/Milho Bt & $4,81 \pm 0,35 \mathrm{~b}$ & $64,06 \pm 4,65 \mathrm{~b}$ \\
Lagarta não Bt/Milho Bt & $3,35 \pm 0,34 \mathrm{c}$ & $0,53 \pm 0,08 \mathrm{a}$ \\
\hline & & $44,67 \pm 4,58 \mathrm{c}$ \\
Lagarta não Bt/Milho não Bt & $8,48 \pm 0,88 \mathrm{a}$ & Safra 2010/2011 \\
Lagarta Bt/Milho não Bt & $8,23 \pm 0,75 \mathrm{a}$ & $100,00 \pm 09,13 \mathrm{a}$ \\
Lagarta Bt/Milho Bt & $4,02 \pm 0,45 \mathrm{~b}$ & $97,05 \pm 10,68 \mathrm{a}$ \\
Lagarta não Bt/Milho Bt & $2,57 \pm 0,41 \mathrm{~b}$ & $0,57 \pm 0,06 \mathrm{a}$ \\
\hline
\end{tabular}

${ }^{(1)}$ Médias seguidas de letras iguais, nas colunas, não diferem pelo teste de Fischer, a 5\% de probabilidade. 
pelos efeitos negativos em componentes do valor adaptativo dos indivíduos, como redução da taxa de sobrevivência (Groeters et al., 1994), aumento do tempo de desenvolvimento (Liu et al., 1999), redução da fecundidade, alteração na razão sexual e insucesso de acasalamento (Groeters et al., 1993), entre outros. Portanto, esse declínio na frequência de indivíduos resistentes na população sem seleção tem sido atribuído ao custo adaptativo.

Já para os insetos coletados no milho Bt e na área de refúgio, na safra 2010/2011, os dois tipos de lagartas (Bt e não $\mathrm{Bt}$ ) alimentadas com folhas de milho $\mathrm{Bt}$ $\mathrm{Cry} 1 \mathrm{Ab}$ não apresentaram diferenças nos índices de adaptação (Tabela 1). Porém, cabe ressaltar que, independentemente da origem das lagartas, quando estas foram alimentadas com folhas de milho $\mathrm{Bt} \mathrm{e}$ não $\mathrm{Bt}$, foram observadas diferenças significativas. Assim, após três safras de uso do milho Bt Cry1Ab, não houve diferença na resposta dessas populações de $S$. frugiperda à proteína Bt. Isso indica que os insetos emergidos do refúgio e da área $\mathrm{Bt}$ estão realmente intercruzando, mantendo o mesmo nível de suscetibilidade. Além disso, os insetos das duas colônias apresentaram índice de adaptação superior a 30\% (redução de $70 \%$ na adaptação) no milho Bt Cry1 Ab. Este resultado confirma a reduzida atividade da proteína Cry1Ab sobre $S$. frugiperda, como observado no bioensaio da safra anterior e por Waquil et al. (2002) e Mendes et al. (2011), o que resulta apenas em uma supressão na população.
Ao se comparar os índices de adaptação de $S$. frugiperda de Sinop aos da população referência (não $\mathrm{Bt}$ ), foram observadas diferenças significativas (Tabela 2). No entanto, quando os insetos foram alimentados com folhas de milho não Bt DKB $390 \mathrm{e}$ milho Bt Vip3Aa20, não houve diferença significativa nos índices de adaptação das duas colônias. No milho Bt Vip3Aa20, os índices foram zerados em razão dos $100 \%$ de mortalidade, o que mostra a alta eficácia dessa proteína no controle de $S$. frugiperda. Já em todos os outros milhos Bt, os índices de adaptação foram menores para as lagartas não Bt.

A maior diferença nos índices foi registrada para as lagartas alimentadas com folhas do milho Bt Cry1F, tendo variado de $5,75 \%$, nas lagartas não expostas ao Bt, a 67,24\%, nas lagartas de milho Bt Cry1A.105/ Cry2Ab2. Além disso, observou-se diferença nos índices entre os dois tipos de lagartas, não $\mathrm{Bt}$ e Bt, alimentadas no milho não Bt Impacto. Neste milho, os índices de adaptação foram menores para as lagartas coletadas em Sinop. No milho não Bt DKB 390, os índices também foram menores $(\mathrm{p} \leq 0,30)$. Dessa forma, esses dados sugerem algum custo adaptativo, o que inclui possível efeito aditivo atribuído à base genética de cada híbrido.

Quando as lagartas das duas colônias foram alimentadas com folhas dos milhos Bt (Cry1A.105/ Cry2Ab2, Cry1F e Cry1Ab/Cry1F), os índices de adaptação foram maiores para as lagartas coletadas em milho Bt, em Sinop. Isso sugere que essa população

Tabela 2. Média \pm erro-padrão do desempenho larval, estimado pelos índices de adaptação e pela razão sexual, de Spodoptera frugiperda proveniente de colônias referência milho não Bt (Lagarta não Bt) e de milho Bt (Lagarta Bt Sp), do município de Sinop, $\mathrm{MT}^{(1)}$.

\begin{tabular}{|c|c|c|c|c|}
\hline Híbrido de milho & Lagarta & Índice absoluto de adaptação & Índice relativo de adaptação & Razão sexual \\
\hline \multirow{2}{*}{ Milho não Bt DKB } & Lagarta não Bt & $7,28 \pm 0,66 \mathrm{a}$ & $100,00 \pm 9,09 \mathrm{a}$ & $0,58 \pm 0,08 \mathrm{a}$ \\
\hline & Lagarta Bt Sp & $6,42 \pm 0,36 a$ & $88,14 \pm 4,92 \mathrm{a}$ & $0,55 \pm 0,08 \mathrm{a}$ \\
\hline \multirow{2}{*}{ Milho Bt VT PRO } & Lagarta não Bt & $0,00 \pm 0,00 \mathrm{a}$ & $0,00 \pm 0,00 \mathrm{a}$ & - \\
\hline & Lagarta Bt Sp & $0,36 \pm 0,14 b$ & $4,96 \pm 1,90 b$ & - \\
\hline \multirow{2}{*}{ Milho Bt Hx } & Lagarta não Bt & $0,15 \pm 0,15 \mathrm{a}$ & $5,75 \pm 2,03 a$ & - \\
\hline & Lagarta Bt Sp & $4,90 \pm 0,46 b$ & $67,24 \pm 6,26 b$ & $0,44 \pm 0,09 \mathrm{a}$ \\
\hline \multirow{2}{*}{ Milho Bt YG } & Lagarta não Bt & $2,48 \pm 0,26 a$ & $34,11 \pm 3,55 a$ & $0,45 \pm 0,11 \mathrm{a}$ \\
\hline & Lagarta Bt Sp & $3,42 \pm 0,26 b$ & $46,94 \pm 3,59 b$ & $0,52 \pm 0,11 \mathrm{a}$ \\
\hline \multirow{2}{*}{ Milho não Bt Imp } & Lagarta não Bt & $6,97 \pm 0,50 a$ & $95,72 \pm 6,92 \mathrm{a}$ & $0,50 \pm 0,08 \mathrm{a}$ \\
\hline & Lagarta Bt Sp & $5,30 \pm 0,33 b$ & $72,79 \pm 4,53 b$ & $0,46 \pm 0,08 \mathrm{a}$ \\
\hline \multirow{2}{*}{ Milho Bt Vip } & Lagarta não $\mathrm{Bt}$ & $0,00 \pm 0,00 \mathrm{a}$ & $0,00 \pm 0,00 \mathrm{a}$ & - \\
\hline & Lagarta Bt Sp & $0,00 \pm 0,00 \mathrm{a}$ & $0,00 \pm 0,00 \mathrm{a}$ & - \\
\hline
\end{tabular}

${ }^{(1)}$ Médias seguidas de letras iguais, nas colunas para cada híbrido, não diferem pelo teste de Fischer, a 5\% de probabilidade. Os híbridos utilizados para alimentação das lagartas foram: P30F35 para as proteínas Cry1F (Milho Bt Hx) e Cry1Ab (Milho Bt YG); DKB 390 não Bt (Milho não Bt DKB) e DKB 390 Bt para a proteína Cry1A.105/Cry2Ab2 (Milho Bt VT PRO); e Impacto não Bt (Milho não Bt Imp) e Impacto Bt para a proteína Vip3Aa20 (Milho Bt Vip). 
já apresenta resistência, e possivelmente cruzada, às proteínas avaliadas. Embora a diferença entre os índices de adaptação das lagartas das duas colônias tenha sido relativamente pequena quando estas foram alimentadas com folhas de milho Bt Cry1A.105/ Cry2Ab2 e Cry1 Ab, para as alimentadas com folhas de milho Bt Cry1F, a diferença foi de aproximadamente 12 vezes, o que evidencia a resistência de $S$. frugiperda à proteína Cry $1 \mathrm{~F}$ (Tabela 2). Esse resultado corrobora dados publicados recentemente sobre a resistência de populações de $S$. frugiperda, oriunda de diferentes regiões brasileiras, à proteína Cry $1 \mathrm{~F}$ (Farias et al., 2014) e sugere atenção para a proteína Cry1A.105/ Cry2Ab2 na região de Sinop.

Com relação ao $\mathrm{TL}_{50}$, nos milhos não $\mathrm{Bt}$, não houve diferença entre as três fontes de insetos, ou seja, lagartas de milho não Bt e de milho Bt Cry1 Ab ou Cry1F (Tabela 3). Independentemente do tipo de lagarta, no milho não $\mathrm{Bt}$, o $\mathrm{TL}_{50}$ variou entre 12 e 15 dias. Já nos híbridos transgênicos, $\mathrm{o} \mathrm{TL}_{50}$ foi menor e variou de 0,02 a 7 dias, dependendo do evento Bt ou da fonte de lagarta. Ainda nos eventos $\mathrm{Bt}$, o $\mathrm{TL}_{50}$ das lagartas previamente expostas às proteínas foi maior do que o das lagartas não Bt. Isso indica que, quanto maior o $\mathrm{TL}_{50}$, maior será o índice de adaptação.

Ao se comparar o $\mathrm{TL}_{50}$ das lagartas apenas nos milhos transgênicos, notou-se que este foi menor no milho que expressa a proteína Cry1F do que no $\mathrm{Bt}$ Cry1 $\mathrm{Ab}$, para ambas as colônias de insetos (não Bt e $\mathrm{Bt}$ ). Também constatou-se baixo $\mathrm{TL}_{50}$ no tratamento que envolveu lagartas de colônias não Bt alimentadas com milho Bt Cry1F. No primeiro dia de observação
(48 horas após a infestação), verificou-se mais de 70\% de mortalidade; assim, o TL ${ }_{50}$ ficou abaixo de 2 dias, mas o valor estimado para $50 \%$ de mortalidade ficou fora do intervalo de dados utilizados para estimar a equação.

Quanto aos parâmetros das equações e ao $\mathrm{TL}_{50}$ de $S$. frugiperda, da população de lagartas de milho Bt Cry1A.105/Cry2Ab2 não diferiu das lagartas da colônia referência, exceto no tratamento com milho Bt Cry1F (Tabela 4). A diferença no $\mathrm{TL}_{50}$ aumentou de 2 para 9 dias nos insetos da colônia de Sinop. Destaca-se que, mesmo nos híbridos Bt que expressam as demais proteínas, como no próprio DKB 390 (Cry1A.105/ Cry2Ab2), no qual os insetos foram coletados, não houve diferença no $\mathrm{TL}_{50}$ entre as duas colônias. Até o momento, não foi encontrado na literatura estudo que tenha avaliado o efeito dessas proteínas Bt sobre o tempo de exposição das lagartas necessário para causar $50 \%$ de mortalidade, ao se considerar apenas os insetos mortos. Sousa (2011) estimou o $\mathrm{TL}_{50}$ para larvas de $S$. frugiperda de diferentes regiões, coletadas e alimentadas com milho não Bt e Bt Cry1 Ab, durante todo o ciclo biológico, e registrou valores de 8 dias, para a população coletada em Nazareno, MG, a 45 dias, para a população coletada em Varjão, MG, o que coincidiu com a maior e a menor mortalidade, respectivamente. Novos estudos que relacionem o tempo letal com os índices de adaptação de S. frugiperda devem ser conduzidos, uma vez que essa variável pode ser importante no monitoramento, para indicar precocemente indícios da evolução de resistência mesmo antes de se obter insetos sobreviventes no campo.

Tabela 3. Tempo letal de Spodoptera frugiperda proveniente de colônias de milho não Bt (Lagarta não Bt), milho Bt Cry1 Ab (Lagarta Bt YG) e milho Bt Cry1F (Lagarta Bt Hx), alimentada com milho não Bt (Milho não Bt) e milho Bt Cry1 Ab (Milho Bt YG) ou Cry1F (Milho Bt Hx) ${ }^{(1)}$.

\begin{tabular}{|c|c|c|c|c|c|}
\hline \multirow[t]{2}{*}{ Milho } & \multirow[t]{2}{*}{ Lagarta } & \multicolumn{3}{|c|}{ Parâmetros da equação de regressão } & \multirow{2}{*}{$\begin{array}{c}\mathrm{TL}_{50} \text { (dias) } \\
\left( \pm \mathrm{IC}_{95}\right)\end{array}$} \\
\hline & & $\mathrm{a}$ & $\mathrm{b}$ & $\mathrm{R}^{2}$ & \\
\hline \multirow{2}{*}{ Milho não Bt } & Lagarta não Bt & 19,77 & 64,39 & 0,74 & $12,12 \pm 2,69 \mathrm{a}$ \\
\hline & Lagarta Bt YG & $-35,75$ & 78,66 & 0,73 & $12,31 \pm 3,86 \mathrm{a}$ \\
\hline \multirow{2}{*}{ Milho Bt YG } & Lagarta não Bt & 26,34 & 44,95 & 0,90 & $3,36 \pm 0,30 \mathrm{a}$ \\
\hline & Lagarta Bt YG & 03,89 & 53,88 & 0,92 & $7,17 \pm 0,96 b$ \\
\hline \multirow{2}{*}{ Milho não Bt } & Lagarta não Bt & 19,77 & 64,39 & 0,74 & $12,12 \pm 2,69 \mathrm{a}$ \\
\hline & Lagarta Bt Hx & 37,34 & 74,76 & 0,69 & $14,96 \pm 3,27 \mathrm{a}$ \\
\hline \multirow{2}{*}{ Milho Bt Hx } & Lagarta não Bt & 74,27 & 13,94 & 0,94 & $0,02 \pm 0,00 \mathrm{a}$ \\
\hline & Lagarta Bt Hx & 22,13 & 47,94 & 0,98 & $3,81 \pm 0,21 b$ \\
\hline
\end{tabular}

${ }^{(1)}$ Médias seguidas de letras iguais, na coluna, não diferem pelo teste de Fisher, a $95 \%$ de probabilidade. $\mathrm{TL}_{50}$, tempo letal médio. IC, intervalo de confiança para $\mathrm{TL}_{50}$.

Pesq. agropec. bras., Brasília, v.51, n.5, p.563-570, maio 2016

DOI: 10.1590/S0100-204X2016000500017 
Tabela 4. Tempo letal de Spodoptera frugiperda proveniente de colônias referência milho não Bt (Lagarta não Bt) e de milho Bt (Lagarta Bt Sp), no município de Sinop, $\mathrm{MT}^{(1)}$.

\begin{tabular}{|c|c|c|c|c|c|}
\hline \multirow[t]{2}{*}{ Híbrido } & \multirow[t]{2}{*}{ Lagarta } & \multicolumn{3}{|c|}{ Parâmetros da equação de regressão } & \multirow{2}{*}{$\begin{array}{c}\mathrm{TL}_{50} \text { (dias) } \\
\left( \pm \mathrm{IC}_{95}\right)\end{array}$} \\
\hline & & $\mathrm{a}$ & $\mathrm{b}$ & $\mathrm{R}^{2}$ & \\
\hline \multirow{2}{*}{ Milho não Bt DKB } & Lagarta não Bt & $-24,16$ & 79,44 & 0,87 & $8,58 \pm 2,31 \mathrm{a}$ \\
\hline & Lagarta Bt Sp & $-22,80$ & 79,57 & 0,87 & $8,22 \pm 2,20 \mathrm{a}$ \\
\hline \multirow{2}{*}{ Milho Bt VT PRO } & Lagarta não Bt & 10,45 & 123,17 & 0,85 & $2,09 \pm 1,50 \mathrm{a}$ \\
\hline & Lagarta Bt Sp & 8,86 & 99,39 & 0,93 & $2,59 \pm 0,95 \mathrm{a}$ \\
\hline \multirow{2}{*}{ Milho Bt YG } & Lagarta não Bt & 0,66 & 69,53 & 0,93 & $5,12 \pm 1,03 a$ \\
\hline & Lagarta $\mathrm{Bt} \mathrm{Sp}$ & 10,10 & 79,52 & 0,96 & $4,66 \pm 0,71 \mathrm{a}$ \\
\hline \multirow{2}{*}{ Milho Bt Hx } & Lagarta não Bt & 28,57 & 60,96 & 0,82 & $2,25 \pm 0,40 \mathrm{a}$ \\
\hline & Lagarta Bt Sp & $-13,54$ & 66,34 & 0,80 & $9,07 \pm 1,89 \mathrm{~b}$ \\
\hline \multirow{2}{*}{ Milho não Bt IMP } & Lagarta não Bt & $-21,03$ & 71,24 & 0,82 & $9,93 \pm 3,62 \mathrm{a}$ \\
\hline & Lagarta Bt Sp & $-45,80$ & 83,65 & 0,66 & $13,97 \pm 4,47 \mathrm{a}$ \\
\hline \multirow{2}{*}{ Milho Bt Vip } & Lagarta não $\mathrm{Bt}$ & 14,52 & 127,40 & 0,82 & $1,90 \pm 1,11 \mathrm{a}$ \\
\hline & Lagarta Bt Sp & 0,00 & 332,19 & 1,00 & $1,41 \pm 0,00 \mathrm{a}$ \\
\hline
\end{tabular}

${ }^{(1)}$ Médias seguidas de letras iguais, na coluna, não diferem pelo teste de Fisher, a $95 \%$ de probabilidade. $\mathrm{TL}_{50}$, tempo letal médio. TC, intervalo de confiança para $\mathrm{TL}_{50}$. Os híbridos utilizados para alimentação das lagartas foram: P30F35 para as proteínas Cry1F (Milho Bt Hx) e Cry1 Ab (Milho Bt YG); DKB 390 não Bt (Milho não Bt DKB) e DKB 390 Bt para a proteína Cry1A.105/Cry2Ab2 (Milho Bt VT PRO); e Impacto não Bt (Milho não Bt Imp) e Impacto Bt para a proteína Vip3Aa20 (Milho Bt Vip).

\section{Conclusões}

1. A proteína CrylAb tem eficiência limitada no controle de Spodoptera frugiperda oriunda da região de Inhaúma, MG, e, após três safras de sua utilização, não mostra evolução de resistência.

2. A população de $S$. frugiperda oriunda de Sinop, $\mathrm{MT}$, apresenta resistência à proteína Cry $1 \mathrm{~F}$ e custo adaptativo para essa característica, bem como algum nível de resistência cruzada às proteínas Cry1 $\mathrm{Ab}$, e Cry1A.105/Cry2Ab2, além de ser altamente sensível à proteína Vip3Aa20, à qual não apresenta resistência cruzada.

3. O tempo letal é maior para as populações de S. frugiperda oriundas de colônias obtidas de plantas $\mathrm{Bt}$ do que para as das plantas não $\mathrm{Bt}$, o que indica evolução de resistência.

\section{Agradecimentos}

Ao Conselho Nacional de Desenvolvimento Científico e Tecnológico (CNPq), pelo apoio financeiro; e ao laboratorista Eustáquio Francisco Souza de Oliveira pela colaboração na realização da pesquisa.

\section{Referências}

AKHURST, R.J.; JAMES, W.; BIRD, L.J.; BEARD, C. Resistance to the Cry1Ac delta-endotoxin of Bacillus thuringiensis in the cotton bollworm, Helicoverpa armigera (Lepidoptera: Noctuidae).
Journal of Economic Entomology, v.96, p.1290-1299, 2003. DOI: $10.1093 /$ jee/96.4.1290.

BARAH, A.; SENGUPTA, A.K. Correlation and regression studies between pupal weight and fecundity of muga silkworm Antheraea assama Westwood (Lepidoptera: Saturniidae) on four different foodplants. Acta Physiologica Hungarica, v.78, p.261-264, 1991.

BOAS práticas agronômicas aplicadas a plantas geneticamente modificadas resistentes a insetos: manejo integrado de pragas. 2014. Disponível em: <http://www.pioneersementes.com.br/ DownloadCenter/Abrasem-2014-Manejo-Integrado-De-Pragas. pdf $>$. Acesso em: 15 set. 2014.

BOREGAS, K.G.B.; MENDES, S.M.; WAQUIL, J.M.; FERNANDES, G.A.W. Estádio de adaptação de Spodoptera frugiperda (J. E. Smith) (Lepidoptera: Noctuidae) em hospedeiros alternativos. Bragantia, v.72, p.61-70, 2013. DOI: 10.1590/ S0006-87052013000100009.

CARRIÈRE, Y.; ELLERS-KIRK, C.; LIU, Y.-B.; SIMS, M.A.; PATIN, A.L.; DENNEHY, T.J.; TABASHNIK, B.E. Fitness costs and maternal effects associated with resistance to transgenic cotton in the pink bollworm (Lepidoptera: Gelechiidae). Journal of Economic Entomology, v.94, p.1571-1576, 2001. DOI: 10.1603/0022-0493-94.6.1571.

CÉLERES. Informativo biotecnologia. 2013. Disponível em: $<$ http://celeres.com.br/wordpress/wp-content/uploads/2013/12/ IB13021.pdf $>$. Acesso em: 10 out. 2014.

COMISSÃO TÉCNICA NACIONAL DE BIOSSEGURANÇA. Parecer técnico $n^{\circ}$ 2052/2009. Liberação comercial de milho geneticamente modificado. 2009. Disponível em: <http://www2. mcti.gov.br/index.php/content/view/14254.html>. Acesso em: 25 out. 2011.

COUSTAU, C.; CHEVIllon, C.; FFRENCH-CONSTANT, R. Resistance to xenobiotics and parasites: can we count the cost? 
Trends in Ecology \& Evolution, v.15, p.378-383, 2000. DOI: 10.1016/S0169-5347(00)01929-7.

CRUZ, J.C. (Ed.). Cultivo do milho. 6.ed. Sete Lagoas: Embrapa Milho e Sorgo, 2010. (Embrapa Milho e Sorgo: Sistema de produção). Disponível em: <http://www.cnpms.embrapa.br/ publicacoes/milho_6_ed/index.htm>. Acesso em: 19 ago. 2012.

FARIAS, J.R.; ANDOW, D.A.; HORIKSOSHI, R.J.; SORGATTO, R.J.; FRESIA, P.; SANTOS, A.C.; OMOTO, C. Field-evolved resistance to Cry1F maize by Spodoptera frugiperda (Lepidoptera: Noctuidae) in Brazil. Crop Protection, v.64, p.150-158, 2014. DOI: 10.1016/j.cropro.2014.06.019.

FERRÉ, J.; VAN RIE, J. Biochemistry and genetics of insect resistance to Bacillus thuringiensis. Annual Review of Entomology, v.47, p.501-533, 2002. DOI: 10.1146/annurev. ento.47.091201.145234.

GASSMANN, A.J.; CARRIÈRE, Y.; TABASHNIK, B.E. Fitness costs of insect resistance to Bacillus thuringiensis. Annual Review of Entomology, v.54, p.147-163, 2009. DOI: 10.1146/annurev. ento.54.110807.090518.

GOMEZ, S.A.; MOSCARDI, F.; SOSA-GÓMEZ, D.R. Suscetibilidade de Spodoptera frugiperda a isolados geográficos de um vírus de poliedrose nuclear. Pesquisa Agropecuária Brasileira, v.34, p.1539-1544, 1999. DOI: 10.1590/ S0100-204X1999000900003.

GROETERS, F.R.; TABASHNIK, B.E.; FINSON, N.; JOHNSON, M.W. Fitness costs of resistance to Bacillus thuringiensis in the diamondback moth (Plutella xylostella). Evolution, v.48, p.197-201, 1994. DOI: $10.2307 / 2410015$.

GROETERS, F.R.; TABASHNIK, B.E.; FINSON, N.; JOHNSON, M.W. Resistance to Bacillus thuringiensis affects mating success of the diamondback moth (Lepidoptera, Plutellidae). Journal of Economic Entomology, v.86, p.1035-1039, 1993. DOI: 10.1093/ jee/86.4.1035

HUANG, F.; QURESHI, J.A.; MEAGHER JR, R.L.; REISIG, D.D.; HEAD, G.P.; ANDOW, D.A.; NI, X.; KERNS, D.; BUNTIN, G.D.; NIU, Y.; YANG, F.; DANGAL, V. Cry1F resistance in fall armyworm Spodoptera frugiperda: single gene versus pyramided Bt maize. PLoS One, v.9, e112958, 2014. DOI: 10.1371/journal. pone.0112958.

JANMAAT, A.F.; MYERS, J.H. The cost of resistance to Bacillus thuringiensis varies with the host plant of Trichoplusia ni. Proceedings of the Royal Society B: Biological Sciences, v.272, p.1031-1038, 2005. DOI: 10.1098/rspb.2004.3040.

LIU, Y.-B.; TABASHNIK, B.E.; DENNEHY, T.J.; PATIN, A.L.; BARTLETT, A.C. Development time and resistance to Bt crops. Nature, v.400, p.519, 1999. DOI: 10.1038/22919.

MARTINELLI, S.; OMOTO, C. Resistência de insetos a plantas geneticamente modificadas: relevância da implantação de estratégias proativas de manejo da resistência. Biotecnologia, Ciência \& Desenvolvimento, v.34, p.67-77, 2005.

MENDES, S.M.; BOREGAS, K.G.B.; LOPES, M.E.; WAQUIL, M.S.; WAQUIL, J.M. Respostas da lagarta-do-cartucho a milho geneticamente modificado expressando a toxina Cry 1A(b). Pesquisa Agropecuária Brasileira, v.46, p.239-244, 2011. DOI: 10.1590/S0100-204X2011000300003.

OLIVEIRA, C.M.; AUAD, A.M.; MENDES, S.M.; FRIZZAS, M.R. Crop losses and the economic impact of insect pests on Brazilian agriculture. Crop Protection, v.56, p.50-54, 2014. DOI: 10.1016/j.cropro.2013.10.022.

PEREIRA, E.J.G.; STORER, N.P.; SIEGFRIED, B.D. Inheritance of Cry1F resistance in laboratory-selected European corn borer and its survival on transgenic corn expressing the Cry1F toxin. Bulletin of Entomological Research, v.98, p.621-629, 2008. DOI: 10.1017/ S0007485308005920.

RESENDE, D.C.; MENDES, S.M.; WAQUIL, J.M.; DUARTE, J. de O.; SANTOS, F.A. Adoção da área de refúgio e manejo de resistência de insetos em milho Bt. Revista de Política Agrícola, ano 23, p.119-128, 2014.

SÁ, V.G.M. de; FONSECA, B.V.C.; BOREGAS, K.G.B.; WAQUIL, J.M. Sobrevivência e desenvolvimento larval de Spodoptera frugiperda (J. E. Smith) (Lepidoptera: Noctuidae) em hospedeiros alternativos. Neotropical Entomology, v.38, p.1-8, 2009. DOI: 10.1590/S1519-566X2009000100012.

SOUSA, F.F. Desenvolvimento de Spodoptera frugiperda em Milho Bt: influência em características de história de vida e crescimento populacional. 2011. 35p. Dissertação (Mestrado) Universidade Federal de Viçosa, Viçosa.

STORER, N.P.; BABCOCK, J.M.; SCHLENZ, M.; MEADE, T.; THOMPSON, G.D.; BING, J.W.; HUCKABA, R.M. Discovery and characterization of field resistance to $\mathrm{Bt}$ maize: Spodoptera frugiperda (Lepidoptera: Noctuidae) in Puerto Rico. Journal of Economic Entomology, v.103, p.1031-1038, 2010. DOI: 10.1603/ EC10040.

TABASHNIK, B.E.; BRÉVAULT, T.; CARRIÈRE, Y. Insect resistance to genetically engineered crops: successes and failures. ISB News Report: Agricultural and Environmental Biotechnology, Jan. 2014. Available at: <http://www.isb.vt.edu/news/2014/Jan 14 . pdf $>$. Accessed on: 20 July 2014.

VAN RENSBURG, J.B.J. First report of field resistance by the stem borer, Busseola fusca (Fuller) to Bt-transgenic maize. South African Journal of Plant and Soil, v.24, p.147-151, 2007. DOI:1 0.1080/02571862.2007.10634798.

WAQUIL, J.M.; VILLELA, F.M.F.; FOSTER, J.E. Resistência do milho (Zea mays L.) transgênico (Bt) à lagarta-do-cartucho, Spodoptera frugiperda (Smith) (Lepidoptera: Noctuidae). Revista Brasileira de Milho e Sorgo, v.1, p.1-11, 2002. DOI: 10.18512/1980-6477/rbms.v1n3p1-11.

Recebido em 2 de janeiro de 2015 e aprovado em 11 de fevereiro de 2016 